\title{
SAN BLAS: DEL OCASO AL RENACIMIENTO. PARADIGMA TEMPRANO DE GESTIÓN DEL PATRIMONIO EN EL SUR PERÚANO. EL CASO DEL BARRIO HISTÓRICO DE SAN BLAS DURANTE LA GESTIÓN MUNICIPAL 1990-1993 ${ }^{\left[{ }^{(*)}\right.}$
}

\author{
SAN BLAS: FROM DECLINE TO REBIRTH. EARLY PARADIGM OF HERITAGE MANAGEMENT IN \\ THE PERUVIAN SOUTH. THE CASE OF THE HISTORIC NEIGHBORHOOD OF SAN BLAS DURING \\ THE 1990-1993 MUNICIPAL GOVERNMENT
}

\author{
MAGALY GALLARDO DEL CASTILLL $0^{[\star]}$, EDGAR CASAVERDE ZAMALLOA ${ }^{(\star \star)} Y$ JORGE PÉREZ BRAVO $0^{[\star \star \star]}$ \\ Universidad Nacional San Antonio Abad del Cusco (Perú) \\ arqgallardodc@yahoo.es_edcazam@hotmail.com jorge_artec@hotmail.com
}

Fecha de recepción: 08 de agosto de 2018

Fecha de aprobación: 26 de noviembre de 2018

\section{RESUMEN}

La presente investigación analiza la política de gestión aplicada en las intervenciones realizadas en el Barrio Histórico de San Blas, emplazado en el Centro Histórico de Cusco, durante el periodo 19901993, gestión municipal del burgomaestre, abogado y político Daniel Estrada Pérez "Qosqoruna". Dichas intervenciones, reunidas en el documento Obras de Remodelación Integral de antiguo Barrio de THOQO KACHI (San Blas), comprendieron "trabajos de pavimentación de sus pintorescas calles, iluminación moderna, tratamiento de fachadas y aguas pluviales" (Municipalidad del Qosqo, 1993 p. 10), el tratamiento de la plaza y la inserción de paqchas ${ }^{(* * * * *)}$, hecho que generó la apropiación e identificación del vecino sanblaseño con el espacio público, devenir del impacto sociocultural y económico positivo generado a raíz de la intervención en su traza urbana patrimonial.

\section{PALABRAS CLAVE}

Centro histórico; barrio histórico; espacio público; gestión municipal

\section{ABSTRACT}

The following study analyzes the management policy applied to the interventions of the Historical Neighborhood of San Blas, located in the Historic Center of Cusco during the period from 1990 to 1993 , under the municipal government of the mayor of the city of Cusco, lawyer and politician Daniel Estrada Pérez "Qosqoruna". Said interventions, collected in the document Works of Integral Remodeling of the old Neighborhood of THOQO KACHI (San Blas), included "paving works of its picturesque streets, modern lighting, treatment of facades and rainwater" (Municipalidad del Qosqo, 1993 p. 10), the treatment of the Plaza and the insertion of paqchas ${ }^{(* * * * *)}$. As a result, the neighbors of San Blas appropriated and identified with the public space, the outcome of the positive sociocultural and economic impact of the intervention in its heritage urban plan.

\section{KEYWORDS}

Historical Center; Historical Quarter; public space; municipal government

(*) El presente artículo se desarrolló en junio de 2018, como parte del trabajo de investigación realizado durante el curso Taller de Conservación de Centros Históricos, a cargo del Dr. Arq. José Hayakawa Casas, de la maestría en Gestión del Patrimonio Cultural, Centros y Sitios Históricos de la Universidad Nacional San Antonio Abad del Cusco (UNSAAC). ${ }^{(* *)}$ Arquitecta por la UNSAAC, con experiencia en gestión, evaluación y ejecución de proyectos de inversión en los sectores privado y público. Actualmente es supervisora de obra en la Dirección Desconcentrada de Cultura - Cusco del Ministerio de Cultura, del Proyecto de Inversión Pública Restauración y Puesta en Valor del Monumento Histórico Artístico Templo San Juan Bautista de Coporaque - Yauri - Espinar.

${ }^{(* * *)}$ Arquitecto por la UNSAAC, Consultor de proyectos de infraestructura pública y privada, con experiencia en supervisión y auditoria en obras públicas. Interés y dominio en tecnología 3D y fabricación digital.

$\left.{ }^{* * * *}\right)$ Arquitecto por la UNSAAC, con experiencia profesional especializada en evaluación y ejecución de proyectos de restauración de inversión pública en el Plan COPESCO Nacional. Gerente de la empresa JP\&CG, dedicada a la asesoria y construccion de equipamiento turístico.

(*****) Piletas, en quechua.

(******) Pools, in Quechua. 
devenir Vol. 6, N¹1, ENERO - JUNIO 2019, PP. 25-48 - ESTUdIOS I ISSN 2312-7562 I E-ISSN 2616-4949

UnIVERSIDAD NACIONAL DE INGENIERÍA, LIMA

doi: https://doi.org/10.21754/devenir.v6i11.632

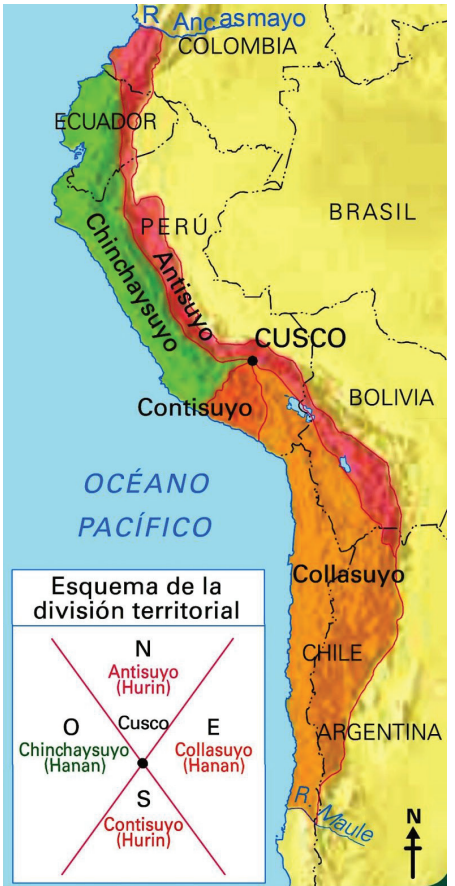

Figura 1. Mapa del Tawantinsuyo, Estado de los inkas. Recuperado de www.pinterest.com/ pin/298293175306598629/?lp=true

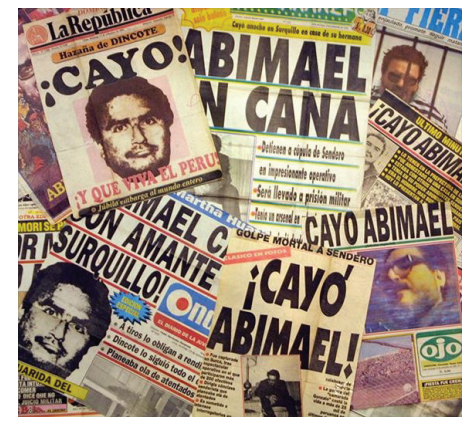

Figura 2. A 24 años de la captura de Abimael Guzmán:Así informóla prensa. Recuperado de https://peru.com/ actualidad/mi-ciudad/24-anos-captura-abimael-guzman-asi-informo-prensa-noticia-474141
El Perú, país latinoamericano geográficamente diverso, se extiende a lo largo de tres regiones tradicionales: costa, sierra y selva. Además, se identifican en su territorio ocho pisos ecológicos, que albergan 54 de los 62 climas del mundo, por lo que posee ingentes recursos naturales, y una de las mayores diversidades de flora y fauna del planeta.

En el área correspondiente a la región denominada sierra, a 3,400 m s. n. m., se encuentra la ciudad del Cusco, antigua capital del Tawantinsuyo, Estado de los inkas, cuyo actual nombre proviene del original Qosqo, que significa ombligo en quechua, razón por la que es conocida por propios y ajenos como el "Ombligo del mundo". Esta ciudad fue incluida el 9 de diciembre de 1983 en la Lista de Patrimonio Mundial de la Organización de las Naciones Unidas para la Educación, la Ciencia y la Cultura (Unesco): "La ciudad fue distinguida como uno de los bienes culturales de valor universal de la Humanidad" (Samanez, 2010, pp. 13-16). Dicho reconocimiento motivó que el Congreso de la República del Perú, mediante la Ley №23765, en diciembre del mismo año, la declare "Cusco, Patrimonio Cultural del Mundo". Estos reconocimientos se sumaron a una lista de reconocimientos previamente recibidos: "Cusco, Capital Arqueológica de Sudamérica", otorgado en 1932 durante el $25^{\circ}$ Congreso Internacional de Americanistas, celebrado en La Plata, Argentina; "Cusco, Patrimonio Cultural del Mundo", emitido en 1978 durante la Reunión de Alcaldes de Milán; "Cusco, Capital Histórica del Perú", título entregado en 1993 por el Congreso de la República del Perú, contenido en el Art. 49 de la Constitución Política del Perú del mismo año (ver Figura 1).

En los años 80 en el Perú, se discutían temas políticos en favor de la agenda de los dos grandes bloques económicos, el sistema socialista y el capitalismo, mientras que se dejaban de lado los temas locales, territoriales y las dinámicas internas. Sin embargo, germinaba ya el tema de la descentralización con el inicio de la regionalización.

Al inicio de los 90, cuando llegaba a su fin el gobierno de Alan García, el Perú se encontraba atravesando una grave crisis económica, ocasionada por las carencias de un Estado ineficiente, burocrático, corrupto y centralista. Es en esa coyuntura que Alberto Fujimori inicia su primer gobierno, caracterizado por un corte autoritario (autogolpe de Estado del 5 de abril de 1992), por la derrota del terrorismo y la introducción de reformas liberales en la economía. La política de regionalización iniciada por Alan García sería abortada por Fujimori, en razón de los problemas administrativos y limítrofes que generó: se trataba de una división en 12 regiones, conformadas mediante el agrupamiento de dos o tres departamentos, cada cual con un Gobierno regional de tipo parlamentario. Según dicha división, Cusco, Madre de Dios y Apurímac conformaban la entonces flamante Región inka (Contraloria General de la República, 2014).

Después del autogolpe del 5 de abril de 1992, el Gobierno encabezado por Fujimori intervino los Gobiernos regionales (Decreto Ley N ${ }^{\circ} 25432$ ) y dispuso la instalación de Consejos Transitorios de Administración Regional (CTAR), a cargo de una autoridad designada por el Ministerio de la Presidencia. Debido al descontento ante la conformación de regiones planteada por el gobierno aprista, no se encontró mayor dificultad ni obstáculos para implementar estas medidas. Así, la administración pública del interior del país permaneció a cargo de una duplicidad de autoridades, pues paralelamente las municipalidades provinciales y distritales mantenían, al menos nominalmente, una gran variedad de funciones que debían ejercer en su jurisdicción.

A mediados de 1992, miles de peruanos buscaban en las embajadas de numerosos países un pasaporte para salir del país: la falta de trabajo, el miedo e incluso la especulación en torno a una posible victoria del grupo subversivo Sendero Luminoso (SL) impulsaron este movimiento migratorio. No obstante, si bien esta reacción de parte de un sector de la población generó un notable triunfalismo en $\mathrm{SL}$, la sorpresiva detención de Abimael Guzmán en setiembre del mismo año produjo un giro radical e inesperado en el proceso de violencia política que atravesaba el Perú (ver Figura 2). 
San Blas: Del ocaso al renacimiento. Paradigma temprano de gestión del patrimonio en el Sur Peruano.

EL CASO DEL BARRIO HISTÓRICO DE SAN BLAS DURANTE LA GESTIÓN MUNICIPAL 1990-1993

Magaly leonor Gallardo Del Castillo, Edgar Casaverde Zamalloa y Jorge Benjamín Pérez Bravo

Tabla 1. Competencias del Estado en temas de cultura, patrimonio y urbanismo

\begin{tabular}{|c|c|c|c|c|c|c|}
\hline \multirow[b]{2}{*}{ Nivel de gobierno } & \multirow[b]{2}{*}{ Institución } & \multicolumn{3}{|c|}{ Cultura y patrimonio } & \multicolumn{2}{|c|}{ Urbanismo } \\
\hline & & $\begin{array}{l}\text { Planificar y } \\
\text { normar }\end{array}$ & Gestionar Investigar & Difundir & $\begin{array}{l}\text { Planificar y } \\
\text { normar }\end{array}$ & Gestionar \\
\hline \multirow{4}{*}{ Ministerio de Cultura } & Dirección Desconcentrada de Cultura & & & & & \\
\hline & Biblioteca Nacional & & & & & \\
\hline & Archivo General de la Nación & & & & & \\
\hline & $\begin{array}{l}\text { Instituto Nacional de Radio y Televi- } \\
\text { sión del Perú (RTP) }\end{array}$ & & & & & \\
\hline $\begin{array}{l}\text { Ministerio de Vivienda, } \\
\text { Construcción y } \\
\text { Saneamiento }\end{array}$ & $\begin{array}{l}\text { Despacho Viceministerial de Vivienda } \\
\text { y Urbanismo }\end{array}$ & & & & & \\
\hline Gobiernos regionales & Gobierno Regional & & & & & \\
\hline \multirow{2}{*}{ Gobiernos locales } & Gobierno Provincial & & & & & \\
\hline & Gobierno Local & & & & & \\
\hline
\end{tabular}

Tras la desarticulación de SL y el decaimiento del conflicto armado, el modelo neoliberal fue aplicado en el Perú, con lo cual la economía empezó a desarrollarse de manera descontrolada, con énfasis en el factor económico, dejando de lado los factores social, ambiental, cultural y político, entre otros.

Ante este panorama surgió la Ley de Patrimonio № 28296 (2004), aún vigente, que norma a las instituciones del Estado competentes en asuntos de cultura y patrimonio; el Ministerio de Cultura es el responsable de implementar acciones que se enmarcan en los Lineamientos de Política Cultural:

1. Impulsar una perspectiva intercultural.

2. Promover la ciudadanía.

3. Fortalecer la institucionalidad.

4. Alentar la creación.

5. Defensa y apropiación social del patrimonio.

6. Apoyar a las industrias culturales.

7. Promover y difundir las artes. (Ministerio de Cultura, 2019, párr. 3)

Desde el dictado de esta ley, las Municipalidades Provinciales y Distritales concentran las mayores competencias en relación a asuntos patrimoniales y de urbanismo. No obstante, por diferentes razones, la participación de las entidades estatales (Ley N²8296, Cap.ll, Art. 29) no se ha implementado de manera efectiva y suficiente. 


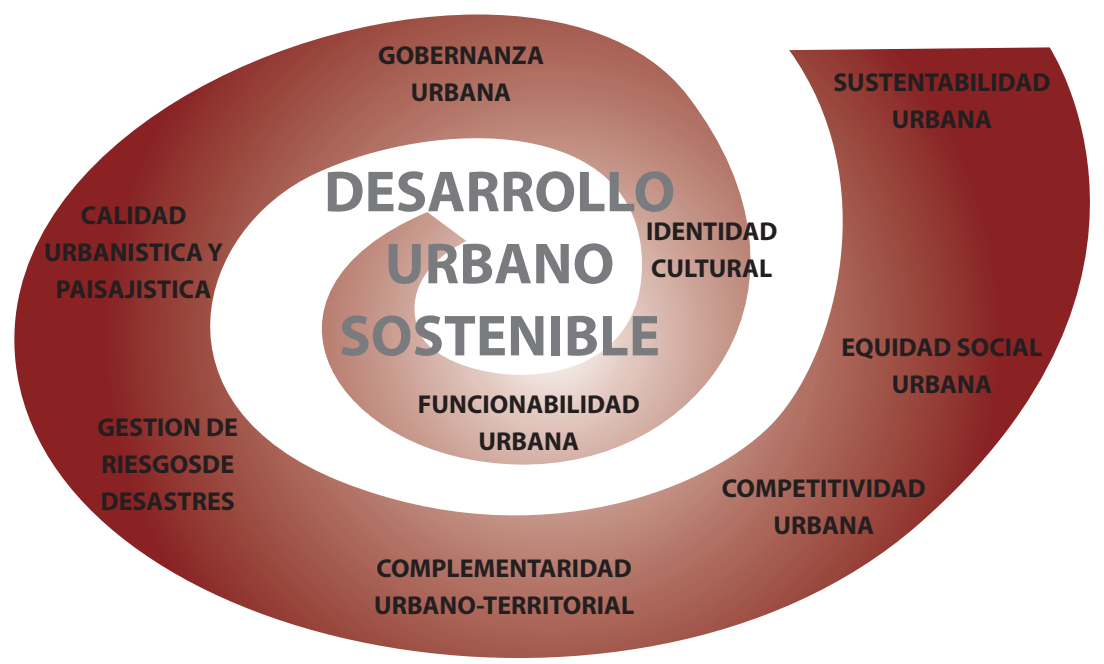

ACCIONES

Figura 3. Acciones y efectos del desarrollo urbano sostenible. Elaboración propia.

El Ministerio de Cultura, organismo responsable de liderar la elaboración de la Política Nacional de Cultura, la define de la siguiente manera:

...resultado de un proceso amplio y participativo.... Las políticas culturales tienen la potencia de crear espacios para imaginarnos como parte de un proyecto común, objetivo que a puertas del cumplimiento de nuestro aniversario doscientos como República, resulta urgente. Por ello, desde el Ministerio de Cultura, estamos trabajando en la construcción de una Política Nacional de Cultura y en su plan de implementación 2018-2021. Ambos instrumentos nos permitirán contar con las herramientas conceptuales, institucionales y de gestión necesarias para promover la transformación social del país a través de la cultura, colocándola en el centro del desarrollo de la ciudadanía y sus comunidades. (Ministerio de Cultura, 2019, párr. 2-3)

La planificación urbana actual considera el desarrollo sustentable de las ciudades, cuyos mayores referentes son el programa Nuestras Ciudades (2012-2015) y el programa Ciudades Sostenibles (2015-2020) del Ministerio de Ambiente.

El ámbito de intervención del PNC está circunscrito a aquellas ciudades que cuenten con una población mayor a 5,000 habitantes. Además, prioriza las ciudades intermedias, aquellas ubicadas en zonas de frontera, las afectadas por fenómenos naturales, y las que resulten estratégicas para el desarrollo nacional.

Según Castillo (2016), en la actualidad, es necesario que el PNC se constituya en un organismo público descentralizado del Sector Vivienda, de manera que cuente con mayor autonomía operativa, capacidad de acción y eficacia en su gestión. Señala que podría denominarse Instituto Nacional de Desarrollo Urbano Sostenible (Inadeus), y que tendría como propósito principal contribuir al desarrollo urbano sostenible de las ciudades y al acondicionamiento territorial sostenible en el Perú.

\section{Panorama de los centros históricos en el Perú: El caso de Cusco}

Parafraseando lo que plantea José Ignacio López Soria (2003) en su libro Para una Filosofía de la Ciudad: los centros históricos del país "no tienen quién los piense". El panorama actual es prueba de que estos resultan presa fácil del vertiginoso crecimiento de las ciudades que los albergan, y de las necesidades comerciales y de sobrevivencia 


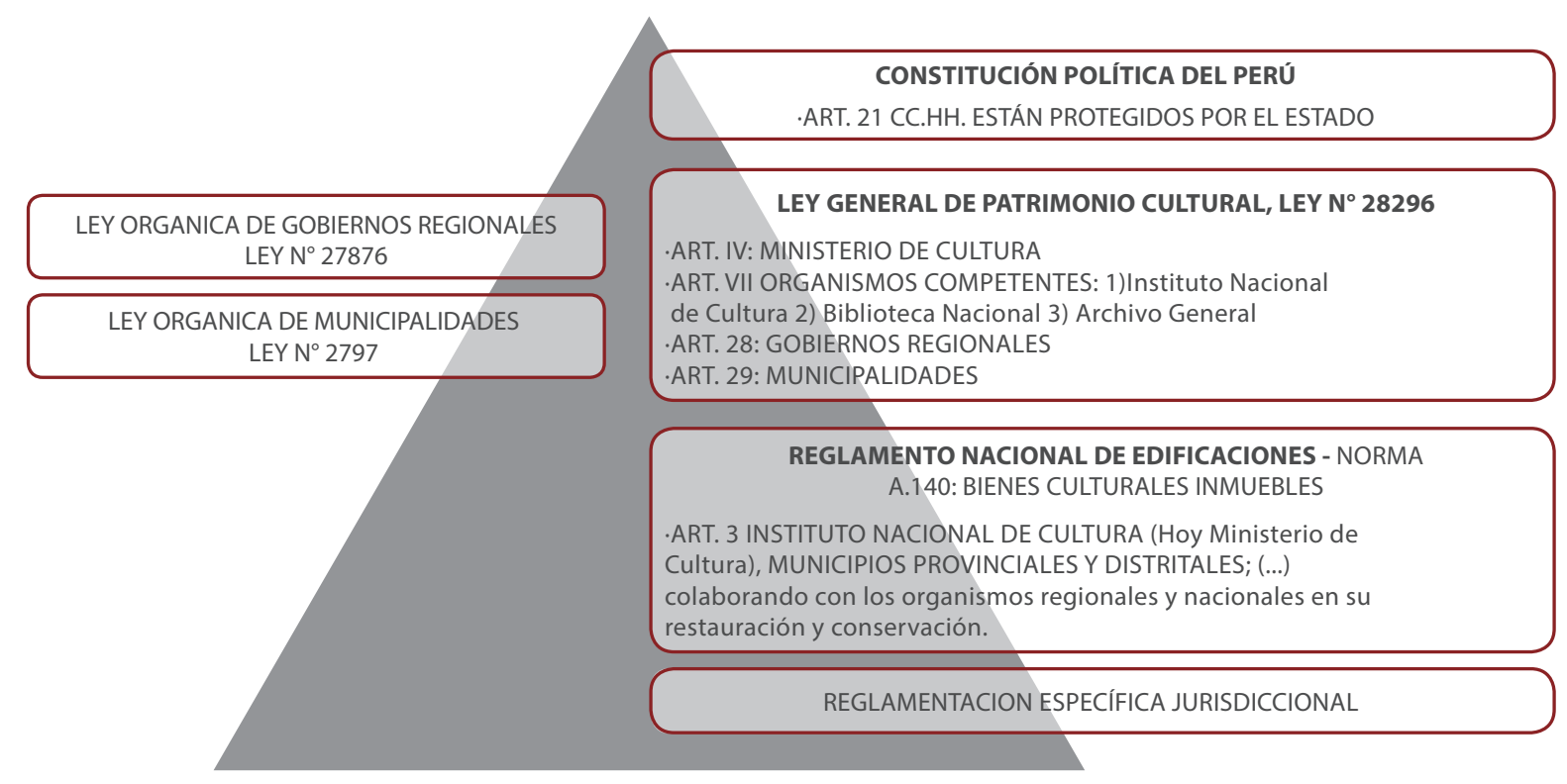

Figura 4. Competencia gestión de centros históricos - sistema jurídico peruano. Elaboración propia.

de quienes los habitan; no obstante, son el olvido y abandono la principal razón de su deterioro y eventual pérdida. Actualmente, los centros históricos sucumben a la explotación del espacio, mercancía codiciada, donde la bien llamada libertad de ciudanía se ejerce más bien como libertinaje. Se prioriza una visión deficiente y sesgada de lo urbano, en desmedro de lo histórico-cultural, a pesar de ser esto último lo que define la particularidad de los centros históricos, por lo que la libertad allí debería ser ejercida "en función de actos voluntarios con objetivos conscientes (políticas): consolidación o conservación" (Carrión, 2000, p. 10).

Es necesaria una visión de futuro de todos los actores sociales, elaborada sobre la base de una franca apuesta por una gestión sustentable de los centros históricos, en la cual "lo antiguo es generador de lo moderno y lo moderno es una forma de conferir existencia a lo antiguo" (Carrión, 2000, p. 11). Por tanto, se deberá tener en cuenta el rol fundamental de estos: "llámese pueblos, ciudades o sectores urbanos que gozan de una trama y/o traza histórica, alta densidad de edificaciones con valor monumental, contextual y ambiental, además de una personalidad, identidad e imagen de valor perfectamente reconocible como entidad sociocultural que resulta de esta síntesis de preexistencias físicas (espacio público y privado) y sociales" (Hayakawa, 2015, p. 211) que no ostenta dicha denominación o título pero que, sin embargo, "poseen valor urbanístico de conjunto, valor documental; histórico-artístico" (Hayakawa, 2015, p. 211).

En el Perú, las instituciones competentes para la gestión de los centros históricos se encuentran enmarcadas en la normativa vigente. Sin embargo, la normativa o reglamentación específica se encuentra desarticulada, pues no se estipula de manera detallada la relación entre los distintos niveles de gobierno ni se delimitan las atribuciones, facultades y obligaciones, lo cual genera sobreposición de roles y funciones. Además, la normativa se encuentra desactualizada en relación a sus contrapartes internacionales (ver Figura 4).

En el Perú de hoy, toda tratativa e intervención debe enmarcarse en el Reglamento Nacional de Edificaciones, en el cual los centros históricos se encuentran denominados bienes integrantes del Patrimonio Cultural de la Nación, específicamente en la Norma A.140 Bienes Cultural Inmuebles, la misma que en su artículo 1 enuncia que "Los al- 
devenir Vol. 6, N¹1, ENERO - JUNIO 2019, PP. 25-48 - ESTUdIOS I ISSN 2312-7562 I E-ISSN 2616-4949

UnIVERSIDAD NACIONAL DE INGENIERÍA, LIMA

doi: https://doi.org/10.21754/devenir.v6i11.632

Tabla 2. Normativa específica de la ciudad del Cusco en el tiempo

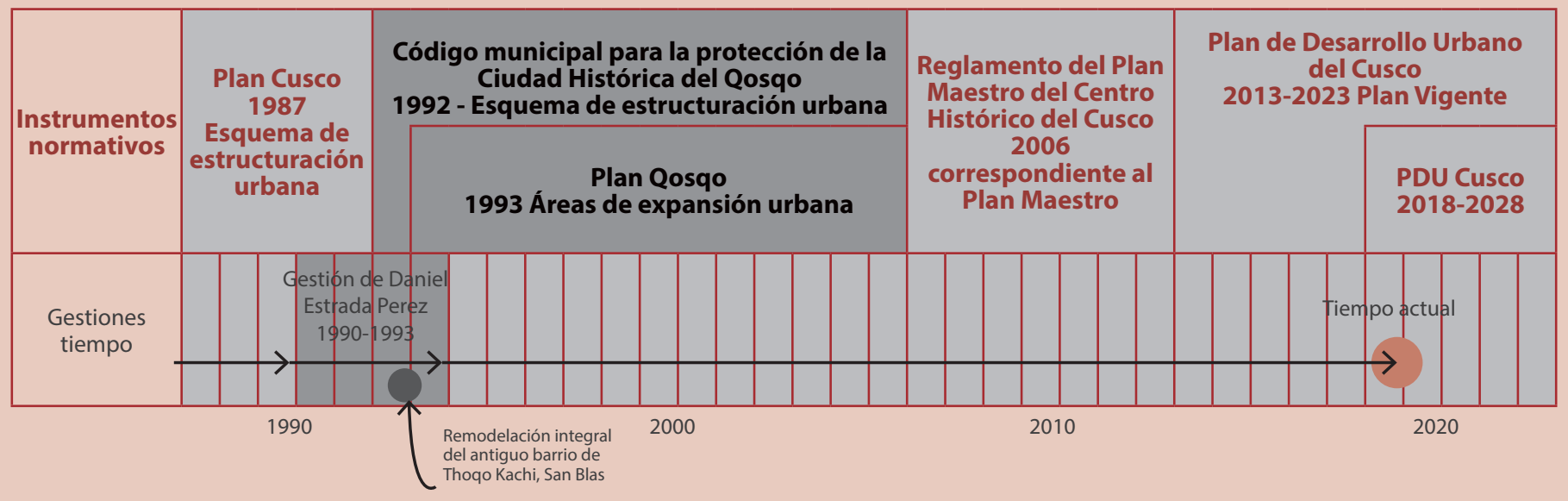

Elaboración propia.

cances de la presente norma... se complementa con las directivas establecidas en los planes urbanos y en las leyes y decretos sobre patrimonio monumental".

La Zona Monumental del Cusco ostenta tal denominación desde 1972, a la publicación de la R.S. N 2900-72-ED, que delimita el área reconocida como Centro Histórico del Cusco.

Durante la gestión del burgomaestre Daniel Estrada Pérez (1991-1993), se encontraba vigente el Plan Cusco (1987), el cual contenía un esquema de estructuración urbana y las bases para el planeamiento del desarrollo del área metropolitana. Respecto de la normativa en cuanto a centros históricos, en el año 1992 se promulgó la Ordenanza Municipal N 02-A/MQ-SG-92 que aprobó el Código Municipal para la Protección de la Ciudad Histórica del Qosqo, normativa que enunció los siguientes como lineamientos para alcanzar su objetivo (ver Tabla 2):

a) Generando una relación armónica, entre el Centro Histórico del Qosqo, su medio natural y las otras áreas de la ciudad, consolidándolas y creando coherencia en ellas.

b) Manteniendo la síntesis de los aportes culturales válidos de cada época de su historia.

c) Evitando el deterioro y propiciando la revitalización de las estructuras físicas de calor cultural, para asegurar la persistencia de los valores heredados, a fin de evitar la pérdida de identidad, así como asegurar la calidad y condición de ente urbano vivo, capaz de brindar dentro de un singular marco físico un digno nivel de vida a sus habitantes.

d) Revitalizando el Centro Histórico mediante el rescate y promoción de los usos existentes adecuados, para generar el desarrollo de la ciudad. (Municipalidad del Qosqo, 1992, p. 10)

En el año siguiente, se formuló el Plan Qosqo, OM N 005-A-MQ/SG-92, que planteó las áreas de expansión urbana a corto, mediano y largo plazo. Ocho años después, en 2001, se firmó un convenio tripartito entre la Unesco, el Instituto Nacional de Cultura (INC) y la Municipalidad Provincial del Cusco para la puesta en marcha del Plan Maestro del Centro Histórico del Cusco, que dio como fruto en 2006 el Reglamento del Plan Maestro del Centro Histórico del Cusco, el mismo que fue aprobado por Ordenanza Municipal $\mathrm{N}^{\circ}$ 140-2005-MPC, cuya vigencia se extendió mediante la OM Nº94-2010-MPC. 


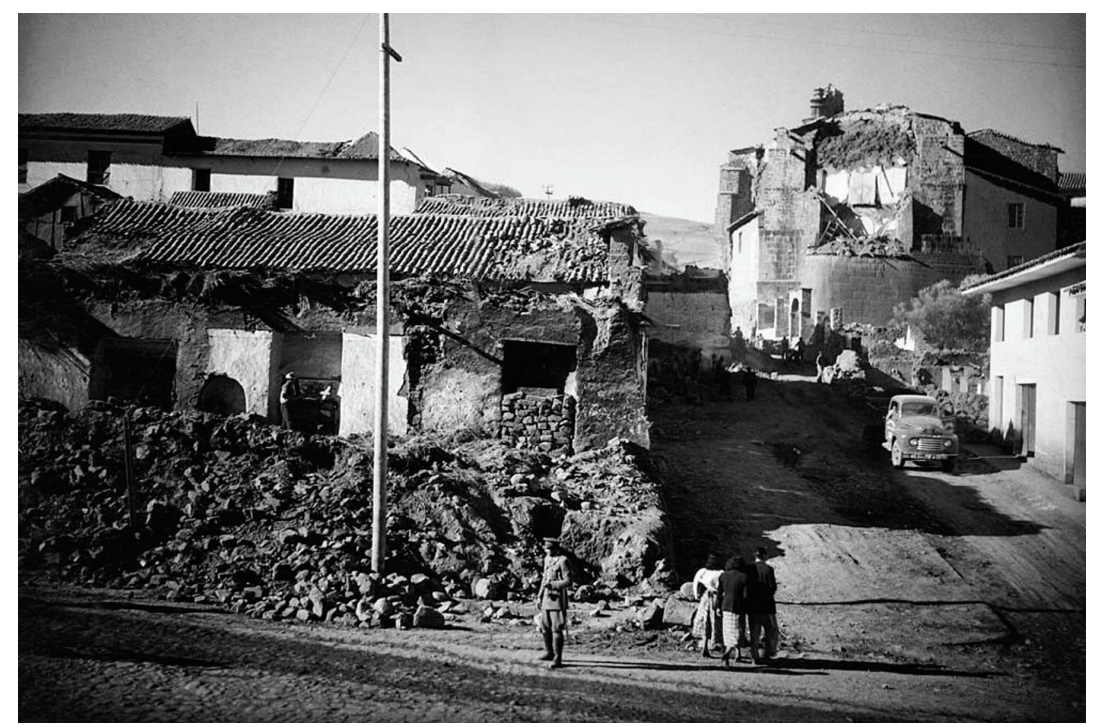

Figura 5. Efectos del terremoto de 1950. Esquina de la av. Sol y la calle Arrayán, al fondo el templo del Qoricancha (fotografía de Martín Chambi). Recuperado de http://limavirreynal.blogspot.com/2008/06/ martin-chambi.htm

Este reglamento se complementó con la Ordenanza Municipal N 011-2011-MPC, que regula la Edificación y Uso De Sótanos y Semisótanos en el Centro Histórico y Zona Monumental Del Cusco, así como con la Ordenanza Municipal № 033-2011-MPC, un reglamento orientado a la recuperación de la imagen urbana y la descontaminación visual, que establece disposiciones técnico normativas para las redes de luz, telefonía, tv por cable, Internet, fibra óptica, agua, gas y similares en la zona monumental y el área de protección del Centro Histórico de la ciudad.

El 25 de setiembre de 2018, se aprobó la Actualización del Plan Maestro del Centro Histórico del Cusco 2018-2028, enmarcada dentro del proyecto Mejoramiento de la Gestión Territorial Urbana en el Centro Histórico de la Provincia del Cusco - Cusco, propuesta de actualización que contempla como objetivo general "como instrumento de gestión técnico y normativo, para la preservación, recuperación y revitalización del patrimonio cultural material e inmaterial del mismo, considerando a la persona como eje fundamental y razón de ser su planeamiento" (Municipalidad Provincial del Cusco, 2018, p. 69), para lo cual considera los siguientes objetivos estratégicos:

1) Garantizar la sostenibilidad de la preservación del CHC.

2) Mejorar los servicios sociales para la población.

3) Mejorar la salubridad pública.

4) Fortalecer la institucionalidad de gestión del Plan Maestro.

5) Revitalizar el Centro Histórico articulándolo con toda la ciudad.

6) Innovar tecnológicamente el CHC.

7) Fortalecer la gestión del turismo vinculada al CHC. (Municipalidad Provincial del Cusco, 2018, p. 73)

Un aspecto resaltante de dicha actualización es su Estrategia General:

Crear la Unidad de Gestión del Plan Maestro como órgano descentralizado de la Municipalidad del Cusco, con carácter democrático, participativo y vinculante con los principales involucra- 
devenir Vol. 6, Nº11, ENERO - JUNIO 2019, PP. 25-48 - ESTUDIOS I ISSN 2312-7562 I E-ISSN 2616-4949

UNIVERSIDAD NACIONAL DE INGENIERÍA, LIMA

doi: https://doi.org/10.21754/devenir.v6i11.632

dos, y que deberá gestionar la inversión estatal, el aporte financiero de fuentes multilaterales de la cooperación técnica internacional así como con el sector privado para ejecutar obras por el sistema de asociación público privada y obras por impuesto, para proyectos estratégicos. La “UNIDAD DE GESTIÓN DE LOS CENTROS HISTÓRICOS DE CUSCO” asumirá el permanente proceso de retroalimentación y actualización del Plan, para garantizar la sostenibilidad del CHC. (Municipalidad Provincial del Cusco, 2018, p. 75)

El modelo exitoso empleado para gestionar el financiamiento de las intervenciones en los centros históricos se elaboró para remediar los efectos del sismo de gran intensidad ocurrido en la ciudad del Cusco el 21 de mayo de 1950 (ver Figura 5). Este modelo primo evidencia cómo el Gobierno peruano enfrentó y financió el reto de reconstruir la ciudad del Cusco: el énfasis estuvo en la reconstrucción de la edilicia patrimonial de carácter monumental, mientras que se dejaron de lado las viviendas de propiedad particular, casas patio del periodo colonial y republicano. Cabe señalar que en aquel entonces el Centro Histórico del Cusco no existía como tal (la trama o traza histórica no estaba delimitada): el Gobierno lo financió aplicando un nuevo impuesto al tabaco, y solicitó la asistencia de la Unesco, que envió dos misiones.

Una primera, en 1951, fue liderada por el Sr. Robert W. Hudgens, director de la Asociación Internacional Americana para el Desarrollo Económico e integrada por la Ing. Lilian Peterson y el Sr. Enrique Sánchez de Lozada. Esta misión encargó al Arq. Luis Miró Quesada Garland la formulación de un plan piloto urbano para la ciudad. Paralelamente el Congreso aprobó una asignación de 60 millones de soles para el Programa de Restauración de Monumentos.

Más tarde, el mismo año, la Unesco envió una nueva misión técnica, esta vez presidida por el Dr. George Kubler, director del Departamento de Arte de la Universidad de Yale, e integrada por el Arq. Oscar Ladrón de Guevara. Producto de esta misión se constituyó la Junta de Reconstrucción y Fomento.

En 1973 se creó el Plan COPESCO, orientado a la creación y desarrollo de infraestructura turística, la construcción y mejoramiento del sistema vial, y la realización de un importante programa de Restauración y Puesta en Valor de Monumentos, el mismo que entre 1975 y 1980 significó la restauración de 20 inmuebles en Cusco y Puno, entre ellos el proyecto PER-71/539 (INC-COPESCO), llevado a cabo con aportes del Gobierno peruano y el Banco Interamericano de Desarrollo (BID). Este proyecto implicó la realización de trabajos de restauración de obras de arquitectura virreinal y prehispánica, entre los cuales destaca la restauración del antiguo Colegio de San Bernardo, el Palacio del Almirante, el Antiguo Hospital de Betlemitas de la Almudena, el seminario San Antonio Abad y el Conjunto Monumental Santo Domingo Qorikancha.

Un nuevo sismo sacudió a la ciudad de Cusco en 1986, cuyo impacto demandó la implementación de un plan de rescate y restauración de sus principales monumentos, acción que estuvo a cargo del INC, y que contó con aportes del Gobierno nacional, el Gobierno regional y la Agencia Española de Cooperación Internacional.

La labor de la AECl, actor en la recuperación de la Manzana 127, fue continuada por la ONG Guamán Poma de Ayala, que recuperó 10 inmuebles del Centro Histórico del Cusco.

\section{El Barrio Histórico de San Blas, "Barrio De Tokocachi"}

Durante la gestión del burgomaestre Daniel Estrada Pérez (1991-1993), se ejecutó la intervención en varios espacios públicos en el Cusco: entre ellas, motivo de análisis del presente estudio, aquella realizada en el Barrio Histórico de San Blas fue uno de los más emblemáticos. 
San Blas: Del ocaso al renacimiento. Paradigma temprano de gestión del patrimonio en el Sur Peruano.

El CASO DEL BARRIO HISTÓRICO DE SAN BLAS DURANTE LA GESTIÓN MUNICIPAL 1990-1993

Magaly Leonor Gallardo Del Castillo, Edgar Casaverde Zamalloa y Jorge Benjamín Pérez Bravo

doi: https://doi.org/10.21754/devenir.v6i11.632

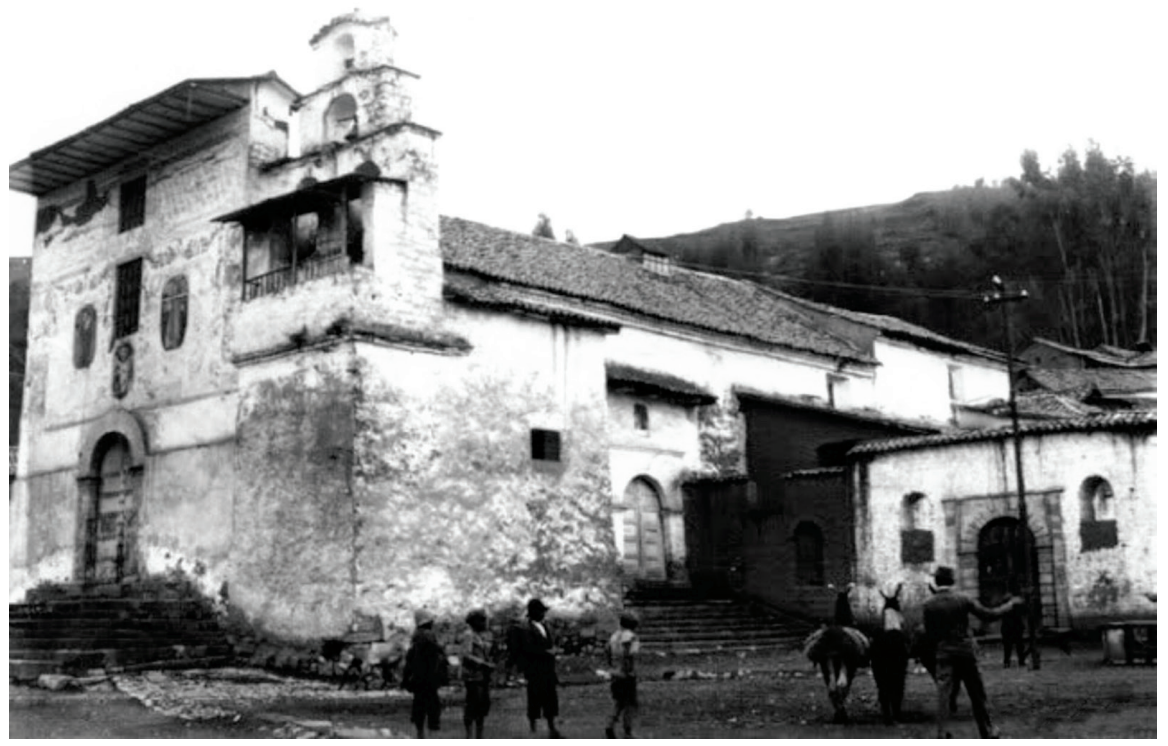

Figura 6. Iglesia de San Blas, 1905. En San Blas. La Destrucción de un Barrio Tradicional (p. 20), 2005.

El Cusco incaico era una ciudad sagrada, de templos y palacios, que imitaba la forma de un puma yacente. La cabeza del felino era la fortaleza de Sacsayhuaman y el cuerpo del mismo, el núcleo urbano que se extendía entre dos ríos, el Shapy y el Tullumayo, que discurren canalizados bajo las calles del mismo nombre. (...) Los barrios donde residían los sectores populares estaban diseminados justamente alrededor de este cinturón de aislamiento y según la mayoría de los cronistas eran doce. Toqokachi (hueco o cueva de sal), el actual San Blas, era uno de tales barrios. (San Blas, 1997, p. 17)

Miguel Mostajo Hinojosa (2018), arquitecto, relata su experiencia como gerente técnico municipal, cargo que fue creado por Estrada ante la necesidad de otorgar mayor eficiencia a la gestión municipal de entonces, pues, como comenta Mostajo, la Municipalidad del Qosqo carecía de una estructura organizacional que viabilizara la ejecución de obras públicas con la celeridad que el ímpetu del alcalde demandaba.

Actualmente conocido como Barrio de San Blas,

En Tokocachi el InkaPachacutec había ordenado la edificación de un templo consagrado al trueno, huaca que había escogido por su huahuaque....En Tokocachi fue hallada la Momia de Pachacutec por el Licenciado Polo de Ondegardo. El Cronista Acosta menciona también el descubrimiento de Polo y describe la Momia o Mallki de Pachacuteq. "Halló traslado e Pantallacta a Tokocache donde se fundó la parroquia de San Blas. Estaba el cuerpo Entero y bien aderezado con cierto betún que parecía vivo. (Calvo Calvo, 1995, p. 47)

El Inca Garcilaso de la Vega (1609) menciona que San Blas en la época inka era uno de los 14 barrios antiguos que rodeaban la ciudad del Cusco. Los terrenos del T'oqoKachi (en quechua, veta o mina de sal) estaban llenos de manantiales de agua salada, que por su sabor resultó ser el ingrediente principal para condimentar los alimentos. La cantidad de manantiales de sal presentes en el área de San Blas propiciaban la formación de arcoíris, por lo que se consideró un lugar adecuado para emplazar el templo donde se adoraba al trueno y al arcoíris.

San Blas era un sector que albergaba considerable cantidad de pobladores, razón que motivó a los invasores llegados de España a arrancar de raíz sus creencias y costum- 
devenir Vol. 6, N¹1, ENERO - JUNIO 2019, PP. 25-48 - ESTUDIOS I ISSN 2312-7562 | E-ISSN 2616-4949

UnIVERSIDAD NACIONAL DE INGENIERÍA, LIMA

doi: https://doi.org/10.21754/devenir.v6i11.632

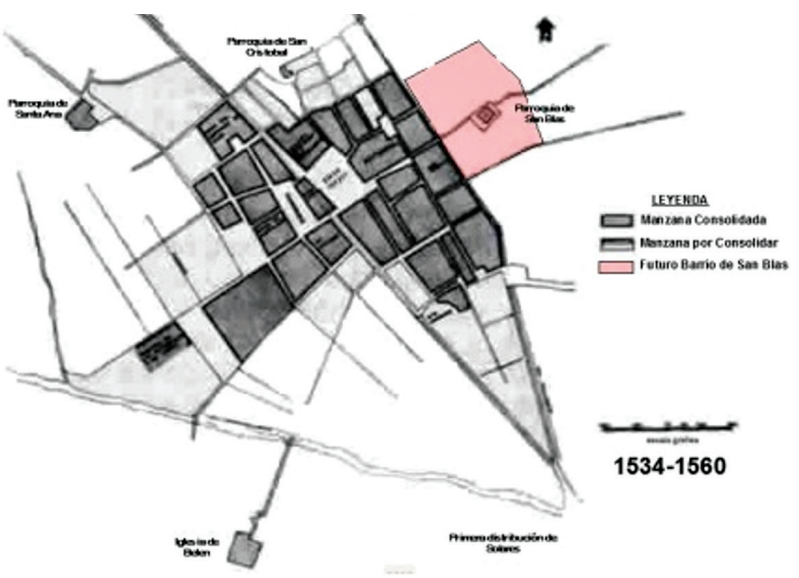

Figura 7. Plano del Centro Histórico del Cusco que evidencia inicios del poblamiento de T'oqokachi, que posteriormente sería el barrio de San Blas (1534-1560). Obsérvese la ubicación de la parroquia de San Blas. En Nuevas Relaciones, Viejas Tradiciones en San Blas (p. 91), por T. A. Valencia Becerra, 2007.

bres, para lo cual construyeron iglesias en los lugares sagrados o utilizados como adoratorios, como es el caso de San Blas:

La parroquia de Iglesia de San Blas fue fundada por el corregidor y Justicia Mayor, licenciado Polo de Ondegardo y erigida por el segundo prelado diocesano Fr. Juan de Zolano, el año de $1562 . .$. El lugar preferido para la dicha fundación fue el antiguo barrio de Ttocco-cache de donde mandó extraer el dicho corregidor, las huacas de los incas: Huiracocha, Tupac Inca Yupanqui y Huaina Cápac. (Covarrubias, 1957, p. 286)

En el mismo lugar donde antes estuviera el adoratorio a la divinidad del arcoíris "Kuichi", se levantó una sencilla iglesia parroquial construida de adobe, de una sola nave con una torre lateral, fundada en 1562 bajo el patrimonio de San Blas... Parroquia de los indios; adyacente a la capilla se dejó un área libre, que los nativos denominan Rayanpata, la plaza de planta rectangular que al consolidar su entorno se convirtió en el eje de un barrio que, con el devenir del tiempo, fue adquiriendo una fisonomía colonial superpuesta a la trama de callejuelas estrechas y torcidas que se adaptan a la variada topografía del antiguo ThoqoKachi. (Municipalidad del Qosqo, 1993, p. 16)

Posteriormente, durante la Colonia, San Blas fue poblada también por españoles. El consecuente mestizaje que tuvo lugar entre la población influenció también en la construcción de sus viviendas:

... a instancias también del obispo Mollinedo, el curo redacto una relación en la que se daba cuenta de la existencia de cuatro ayllus o comunidades de indios en el barrio con un total de 352 indios cabezas de familia en dicho informe, en 1689 se indicaba por otra parte, que en San Blas habitaban "hasta 250 personas españolas de diferentes edades, una en casas propias otras en arredandas" Seguramente de esta convivencia entre indios y españoles fue naciendo ese barrio de fisonomía mestiza en el que convirtió San Blas con el tiempo. ("San Blas", 2005, p. 21)

No obstante la presencia de españoles, Valencia (2007) refiere que San Blas en su mayoría estaba habitado por indígenas, tanto de la región como foráneos; antes del s. XVIII no pertenecía al centro histórico de la ciudad, ya que este estaba delimitado por el río Choquechaca, que se prolongaba hasta San Sebastián. En 1700 aproximadamente, a los ríos canalizados por los inkas se les agregó puentes de cal y canto, lo cual unió el centro histórico con San Blas, y generó algunos cambios, como la llegada de nuevos habitantes, la mayoría dedicados a la extracción y utilización de sal. Posteriormente, se desarrollaron allí labores como fábricas de cal, peletería y curtiem- 
San Blas: Del ocaso al renacimiento. Paradigma temprano de gestión del patrimonio en el Sur Peruano.

EL CASO DEL BARRIO HISTÓRICO DE SAN BLAS DURANTE LA GESTIÓN MUNICIPAL 1990-1993

Magaly leonor Gallardo Del Castillo, Edgar Casaverde Zamalloa y Jorge Benjamín Pérez Bravo

doi: https://doi.org/10.21754/devenir.v6i11.632

Tabla 3. Población tributaria de la parroquia de San Blas, 1962

\begin{tabular}{|c|c|c|c|c|}
\hline Parroquias y ayllus & & NOBLES & ORIGINARIOS & FORASTEROS \\
\hline Parroquia San Blas & & 16 & 62 & 80 \\
\hline Capac & ChrispinTintacana & 3 & 6 & 24 \\
\hline Urincosco & LazaroYllaguaman & 3 & - & 31 \\
\hline Collana & BartolomePomalondo & 5 & 25 & 15 \\
\hline Hatun Yngacona & NicolasCamacondoriYngaYupangui & 5 & 31 & 10 \\
\hline
\end{tabular}

En El Ombligo se pone Piercing. Identidad, Patrimonio y Cambios en el Cuzco (Vol. 1), por L. Nieto Degregori (Ed.), 2009

bre, y se crearon talleres de diferentes oficios, como herrería, costura y confección, carpintería, santería, etc. Por los múltiples oficios que allí se desarrollaban, San Blas fue considerado un suburbio de la ciudad, según plantea Valencia (2007) en su tesis.

En 1762 se realizó una revisita a los tributarios de las ocho parroquias cusqueñas, que se inició con los caciques, gobernadores, alcaldes y demás. El resultado de esta señala que en las mencionadas parroquias estaban inscritos un total de 609 inkas nobles, de los cuales 404 vivían en la parroquia de San Sebastián y 331 en la parroquia de San Jerónimo, ambas pertenecientes a las panacas de Hurin Cusco. En el caso de la parroquia de San Blas, estaban allí registrados 16 nobles, 62 originarios y 80 forasteros, que pertenecían al Hanan Cusco, así como la parroquia de San Cristóbal (ver Tabla 3).

Hacia el siglo XIX San Blas ya estaba incluido dentro del Centro Histórico del Cusco. Sin embargo, se caracterizaba por cierta inaccesibilidad, debido a que la única conexión con la Plaza de Armas era una cuesta empinada, algo difícil de transitar:

Desde la calle de hatumRumiyoc, típica calle cusqueña, estrecha, de Muros incaicos i balconcillos coloniales, donde conviven el alma ciclópea del indio i el espíritu sonador i delicado del castellano, se divisa la cuesta..., lentas, gallardas i cimbreantes, moviendo para un lado i para otro sus largos pescuezos, las llamas hurañas a cuya zaga va una india de multicromo indumento, mostrando sus carnosas i recias pantorrillas con su atado a su espalda.

Ascendiendo por los rudos peldaños de la cuesta que me conduce a la plaza de la parroquia donde palpita, el alma del poblado, de marcado sabor indígena. Escueta silenciosa la encuentro; no hay en ella los aponimios umbrosos del parque moderno ni los bancales que conviden al muelle del descanso. Solo unos apoyos de barro i una fuente de piedra, que está al centro, de donde mana cantarín, un mezquino hilillo de agua constituyen sus tesoros ornamentales.

Resalta en todas partes el ambiente pueblerino de esta rústica barriada... de los ángulos de la plaza parten callejas silenciosas donde la vida es un largo bostezo de pereza i por donde pasa tal cual vecino melancólico i caviloso. Destaca su típica fachada provinciana, llena de pinturas grotescas estropeadas por el tiempo, el templo parroquial de modesta fábrica de barro. (García, 1921, p. 4)

Cusco fue sometido a la modernidad luego del suceso del terremoto del 50: tuvo lugar la creación de nuevos barrios, la formación de nuevos distritos, la apertura de vías de acceso de vehículos. Este hecho generó el desplazamiento de la agricultura que practicaban 
devenir Vol. 6, N¹1, ENERO - JUNIO 2019, PP. 25-48 - ESTUDIOS I ISSN 2312-7562 I E-ISSN 2616-4949

UnIVERSIDAD NACIONAL DE INGENIERÍA, LIMA

doi: https://doi.org/10.21754/devenir.v6i11.632

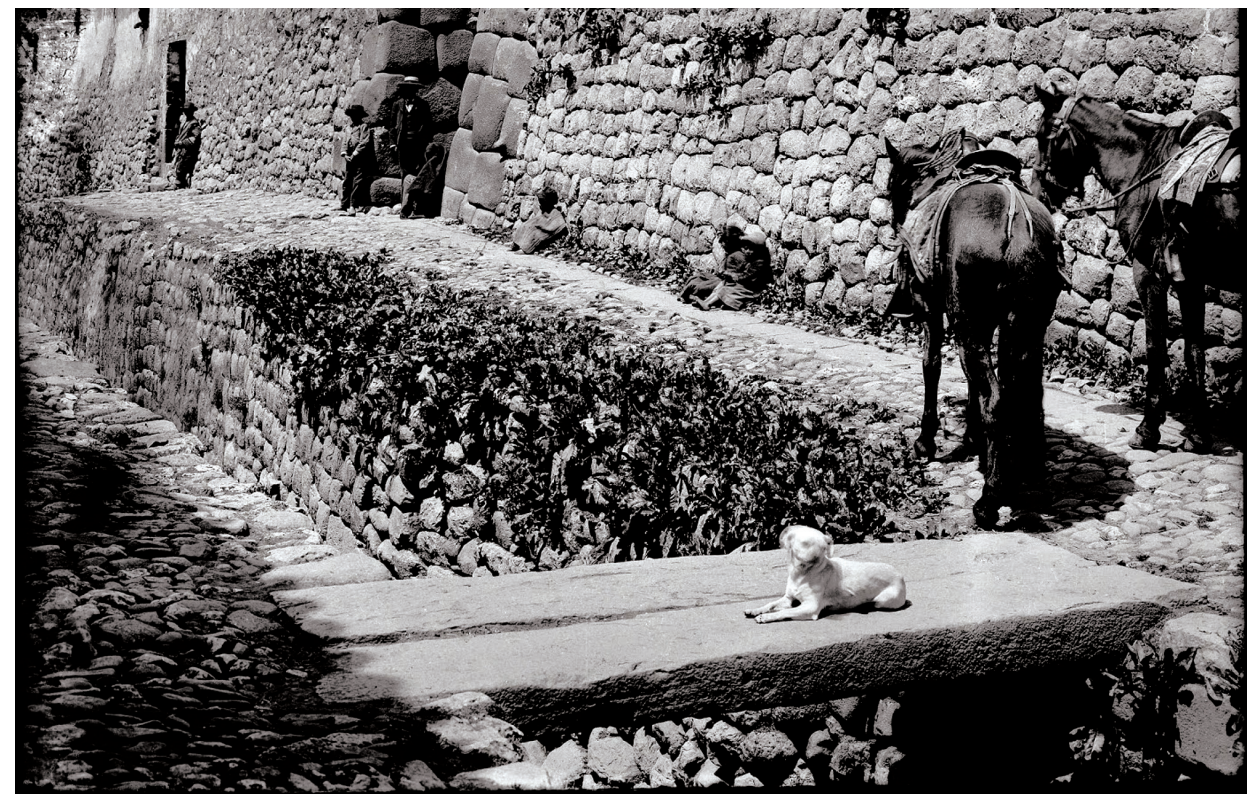

Figura 8. Río Choquechaka antes de la canalización de la calle. En San Blas. La Destrucción de un Barrio Tradicional (p. 23), 2005.

aún en San Blas los pobladores originarios de la zona, lo cual los sometió a la servidumbre, ya que los nuevos oficios eran considerados superiores a la actividad agrícola:

Los artesanos estuvieron sujetos a una serie de construcciones ideológicas y prejuicios raciales que prevalecían no solo en el Cuzco sino en todo el Perú. Los maestros artesanos marcaban su propia distancia social de las clases bajas discriminando a cusqueños que ellos consideraban indios. (Kluggeler, 1985, p. 180)

El sabor indígena de San Blas estaba perdiéndose debido a la presencia de pobladores españoles, casi siempre de escasos recursos económicos, y la generación de oficios, de una nueva identidad barrial en la que prevalecía el mestizaje.

El 27 de abril de 1938 el diario El Comercio del Cusco reportaba algunos incidentes relacionados a los tapados y los agujeros en el barrio, asunto que cada cierto tiempo recuperaba vigencia:

En una casa de San Blas, se hizo excavaciones. Los trece millones de doblones siguen siendo un misterio. Confirmado la denuncia que se adelantara en hacer en su edición de antier nuestro colega EL SOL, y en posesión de datos fidedignos que nos ha sido suministrado por las dependencias del Patronato Arqueológico Departamental, Ofrecemos a nuestros lectores algunos pormenores de excavaciones que varias personas habían formado una comandita para el hallazgo de fabuloso tesoro jesuítico, venía realizando en una casa del callejón de Quiscapata de la parroquia de San Blas. No se pude asegurar hasta este momento, como nos manifiesta en el patronato, si los huaqueros han encontrado o no algún tesoro, pero lo cierto es que habían hecho ya un corte longitudinal de treinta metros por seis de ancho y tres de profundidad en la casa mencionada del barrio de Toccocachi. (El Comercio Del Cusco, 1938, s. p.)

Las casonas del lugar mantuvieron hasta mediados de los años 80 sus estructuras primigenias, que resistieron el terremoto de 1950. En esa época, el deterioro se debía predominantemente a la presión poblacional, la tugurización y la naturaleza modesta de sus edificaciones, pero tras el terremoto de 1986 la mayoría de casonas se encontraban en peligro de colapsar (Valencia Becerra, 2007). 
San Blas: Del ocaso al renacimiento. Paradigma temprano de gestión del patrimonio en el Sur Peruano.

El CASO DEL BARRIO HISTÓRICO DE SAN BLAS DURANTE LA GESTIÓN MUNICIPAL 1990-1993

Magaly Leonor Gallardo Del Castillo, Edgar Casaverde Zamalloa y Jorge Benjamín Pérez Bravo

doi: https://doi.org/10.21754/devenir.v6i11.632

\section{PHAQCHACHAS}

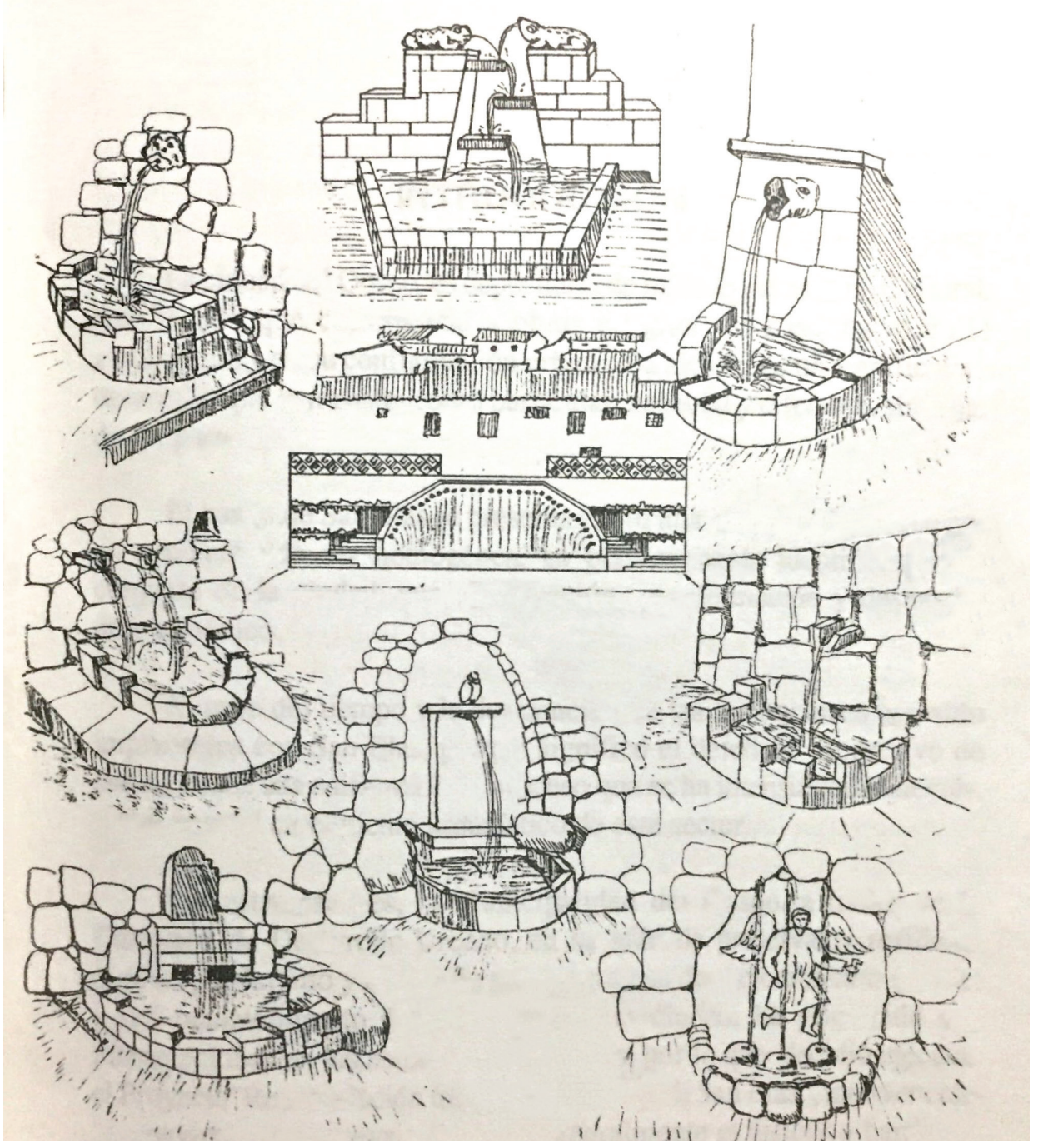

Figura 9. Paqchachas. Archivo personal M. Mostajo.

En 1990, como parte del Proyecto Regional de Patrimonio Cultural y Desarrollo, la Universidad San Antonio Abad del Cusco, y el Instituto Nacional de Investigación y Normalización de la Vivienda, con apoyo de la Unesco, realizaron una investigación en la ciudad del Cusco, que hizo manifiesta la necesidad de conservar los centros históricos para sus habitantes, sin descuidar el patrimonio cultural.

El burgomaestre Estrada Pérez encaró la institucionalidad de la Municipalidad del Qosqo con escasos recursos, poco personal, y frágil presencia en la vida social y política. Sin embargo, contó con la experiencia de Miguel Mostajo Hinojosa, quien laboraba en dicha institución. A partir de entonces, construyó las bases y el equipo que enfrentó el reto de intervenir el Barrio de San Blas, así como las consecuencias del terrorismo de la década de los 80 (Pino Zambrano, 2004), al igual que otros alcaldes en el Perú, como Eduardo Orrego y Alfonso Barrantes en la capital, y Larco Cox y José Mujica en el norte, quienes dentro de sus propias corrientes políticas tuvieron la capacidad política de armar equipos de trabajo, y entender el sentimiento de la población en función al rol y el significado de los gobiernos municipales. 
devenir Vol. 6, N¹1, ENERO - JUNIO 2019, PP. 25-48 - ESTUDIOS I ISSN 2312-7562 | E-ISSN 2616-4949

UNIVERSIDAD NACIONAL DE INGENIERÍA, LIMA

doi: https://doi.org/10.21754/devenir.v6i11.632

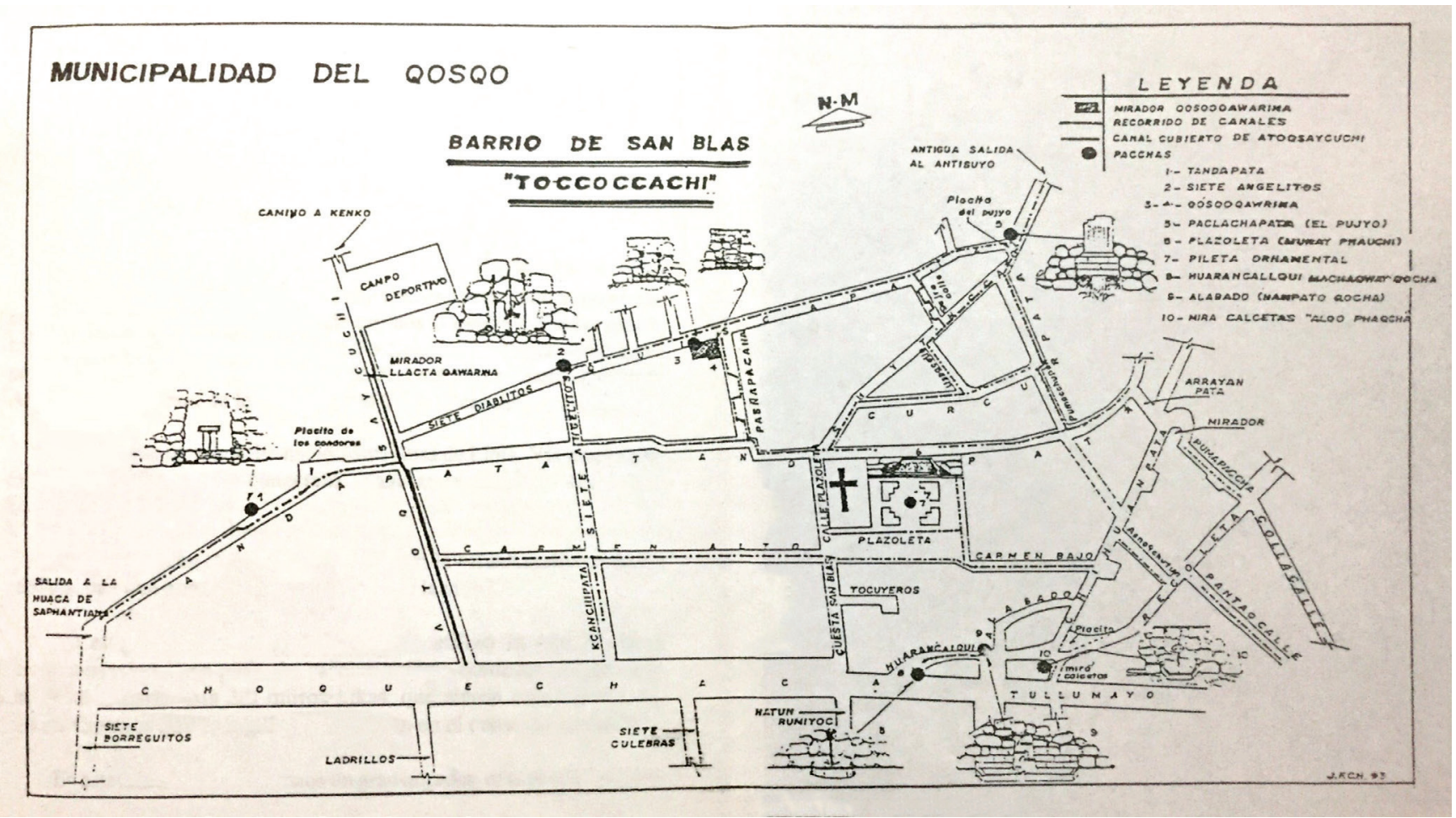

Figura 10. Plano de intervención del Barrio de San Blas, antes T'oqokachi. Archivo personal M. Mostajo.
Pino Zambrano (2004) refiere que en el Cusco se propugnaba que los municipios eran la base y sustento del desarrollo local, responsables del proceso de acumulación de capital social, la construcción de infraestructuras, el fortalecimiento de las capacidades locales, y el cuidado y protección del patrimonio cultural y natural, etc. Dicha postura generó un arduo debate entre las diversas corrientes de izquierda, que defendían la construcción de bases para el desarrollo de la ciudadanía y las dinámicas económicas territoriales.

El arquitecto Mostajo Hinojosa (2018) afirma que la visión y los objetivos principales de esta gestion fueron los siguientes:

- Generar identidad cultural e identificación con la ciudad para forjar un sentido de pertenencia en el poblador local

- Dinamizar la economía de los pobladores del Barrio de San Blas, cuya especialidad era la artesanía

\section{- Lograr que el Barrio de San Blas sea atractivo para el turismo}

- Respecto de la intervención en el Barrio de San Blas, tenía como objetivo de primer orden "conservar la imagen del Barrio, sin alterar su conformación, sino más bien resaltar su arquitectura garantizando la recuperación urbana del Barrio" (Municipalidad del Qosqo, 1993).

La intervención planteada por la gestión municipal en cuestión, "Las Obras de Remodelación Integral del antiguo Barrio de THOQO KACHI (San Blas), comprendió trabajos de pavimentación de sus pintorescas calles, iluminación moderna, tratamiento de fachadas y aguas pluviales" (Municipalidad del Qosqo, 1933, p. 8). Las labores realizadas incluyeron el tratamiento de la plaza de San Blas, así como la inserción de paqchas estratégicamente ubicadas, consideradas por la Municipalidad del Cusco (1993) “un hito 


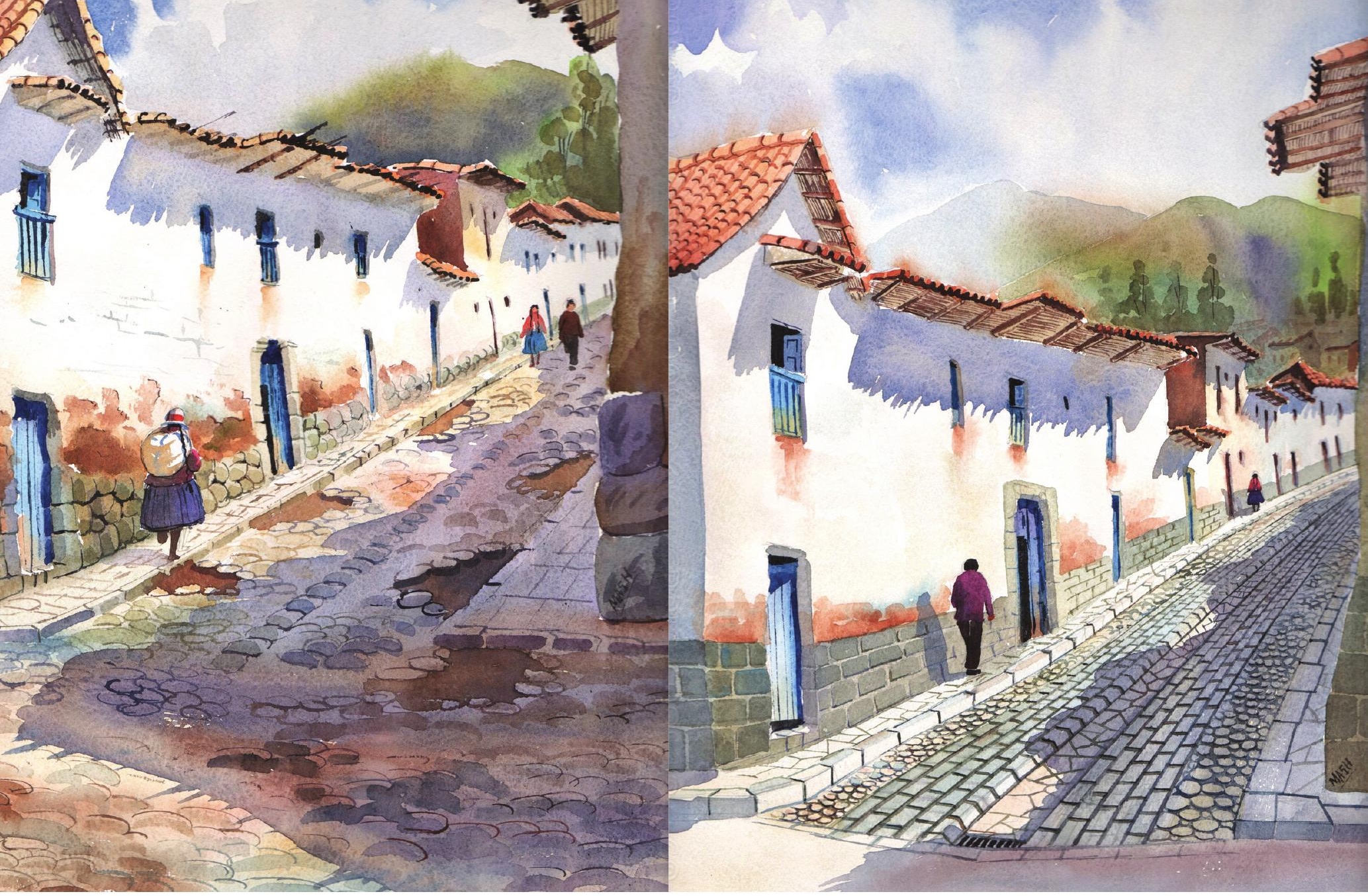

Figura 13. Calle Carmen Alto, antes de la intervención. Archivo personal M. Mostajo.

Figura 14. : Calle Carmen Alto, después de la intervención. Archivo personal M. Mostajo.

miento de vías y del mantenimiento de la imagen de la ciudad, ha priorizado sus intervenciones en zonas monumentales....

Toda intervención que preserve y revalore al Patrimonio Monumental y Artístico no contraviene teórica y prácticamente con una política de regulación urbanística; lejos de ello, debe constituirse en el complemento de la misma, teniendo como primer objetivo el de elevar el nivel del poblador, no solo en términos materiales sino una existencia y convivencia más humana, acogedora y digna para el poblador de cada sector". (Municipalidad del Qosqo, 1993, pp. 7-8)

Para entonces la Zona Monumental a la que se circunscribe San Blas contaba con un conjunto de disposiciones técnico-legales que regían su protección. Estrada Pérez se constituyó en el principal gestor de este barrio, tal como lo evidencia la Ordenanza Municipal $N^{\circ}$ 02-Ha/MQ-SG-92, que aprueba su salvaguarda.

Es interesante remarcar que la intervención realizada por la gestión de Estrada Pérez tuvo la aceptación y apropiación del poblador blaseño: "algunas de estas obras ciertamente tienen el mérito de haber mejorado la escena urbana, en beneficio de la ciudad" (Araoz, 2010, p. 6). Sin embargo, cinco años después, en 1997, el Centro Guamán Poma de Ayala, junto con la Municipalidad del Qosqo, producto del catastro realizado en la ciudad y el centro histórico, concluiría de forma alarmante, respecto del Barrio de San Blas, que "la tendencia más saltante de la década del 90 es la de destrucción, transformación y pérdida irreversible del Barrio de San Blas, especialmente de su patrimonio edificado" (Estrada \& Nieto, 1998, p. 23). Esta conclusión es muestra de que una intervención acertada en su momento, con el transcurrir de los años y ante la falta de visión de las gestiones posteriores, sucumbe y degenera su función principal de barrio-vivienda por el comercial-turístico, víctima de la temida gentrificación. 


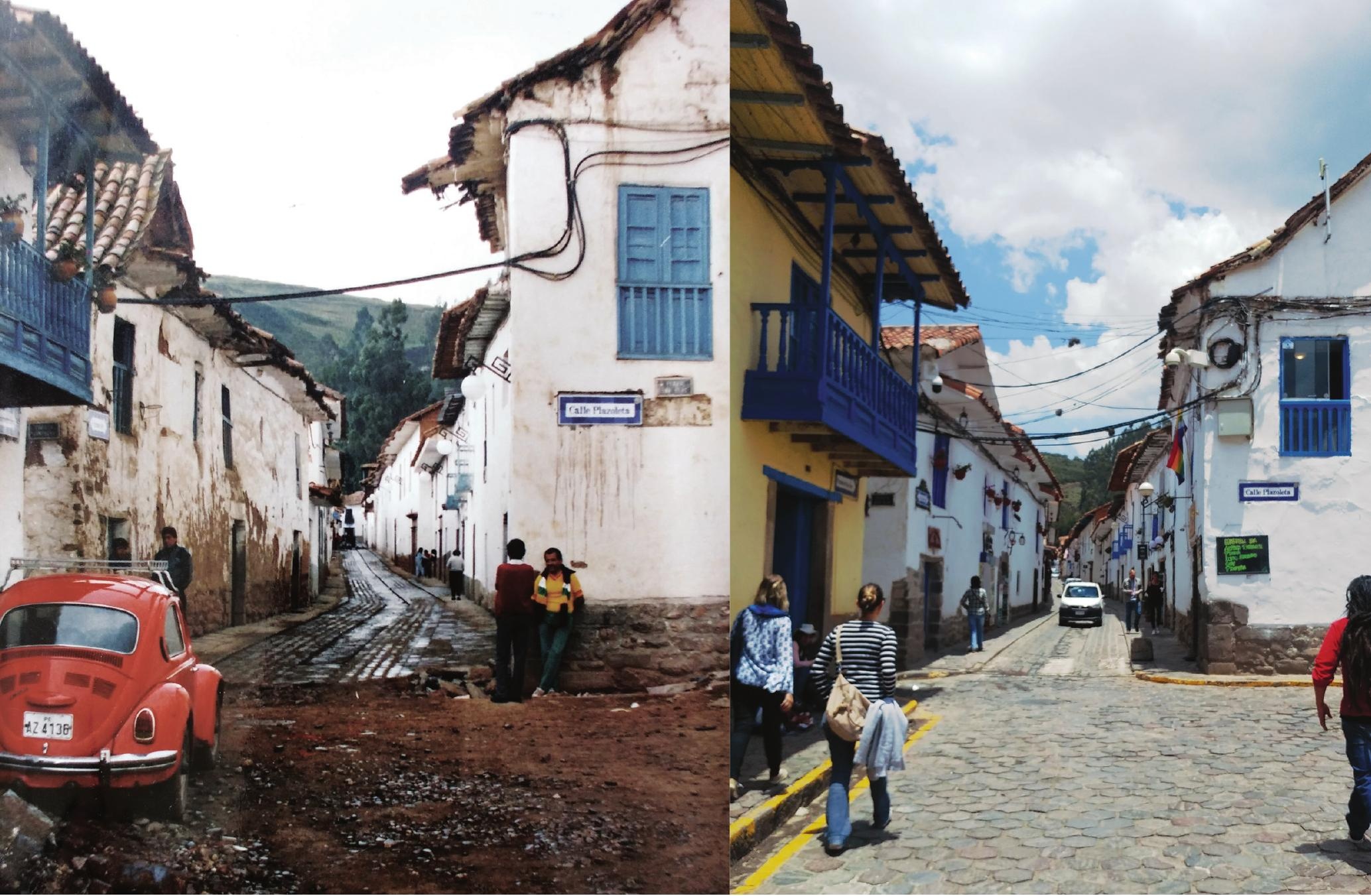

Figura 15. Calle Carmen Alto en 1991, antes de la intervención. Archivo personal M. Mostajo.

Figura 16. Calle Carmen Alto, Barrio de San Blas, noviembre de 2018. Archivo fotográfico de los autores.

Según el Informe Económico de Proyectos y Acciones Ejecutados Ingresos y Gastos de la Municipalidad del Qosqo Periodo 1990 - 1992, dado a conocer en enero de 1993 (ver sección "Anexos"), la intervención realizada en el Barrio de San Blas se consigna dentro del ítem "D. Pavimento Empedrado", (Municipalidad del Qosqo, 1993) con un monto total de $S / .673,033.00$, así como dentro del ítem "Fondo Municipal para el Mejoramiento del Alumbrado Público" (FOMAP), con un monto total de S/. 122,984.00, que en conjunto corresponden a un monto total de S/.796,017.00.

\section{Representación gráfica del proyecto Remodelación Integral Del Antiguo Barrio De San Blas}

Evidencia histórica del proceso de planificación del proyecto es el registro gráfico del estado previo y posterior a la intervención de cada una de las calles que conforman el Barrio de San Blas. Dicho registro se realizó mediante acuarelas (aproximadamente 90), las cuales permiten apreciar los cambios realizados, lo cual revela la intencionalidad proyectual de la gestión (Figura 13, 17, 18 y Tabla 4).

Cabe mencionar que desde 1985, de acuerdo a la Ley $N^{\circ} 24331$, se destinaba el $2 \%$ de la renta que produce el Impuesto General a las Ventas (IGV) de cigarrillos y tabaco, y el $2 \%$ del Impuesto Selectivo al Consumo (ISC) sobre la producción y comercialización de los mismos, al desarrollo, restauración, protección y conservación del patrimonio cultural y monumental del Cusco. La ley que garantizada esta renta como propia de la Municipalidad del Cusco fue derogada por D.L. 261 en 1990, durante el gobierno de Alberto Fujimori.

Entre 1990 y 1993 la Municipalidad del Qosqo contaba como fuentes de financiamiento con los denominados recursos directamente recaudados, entre los cuales se encon- 
RESUMEN EJECUCION DE OBRAS PERIODO 1990 - 1992

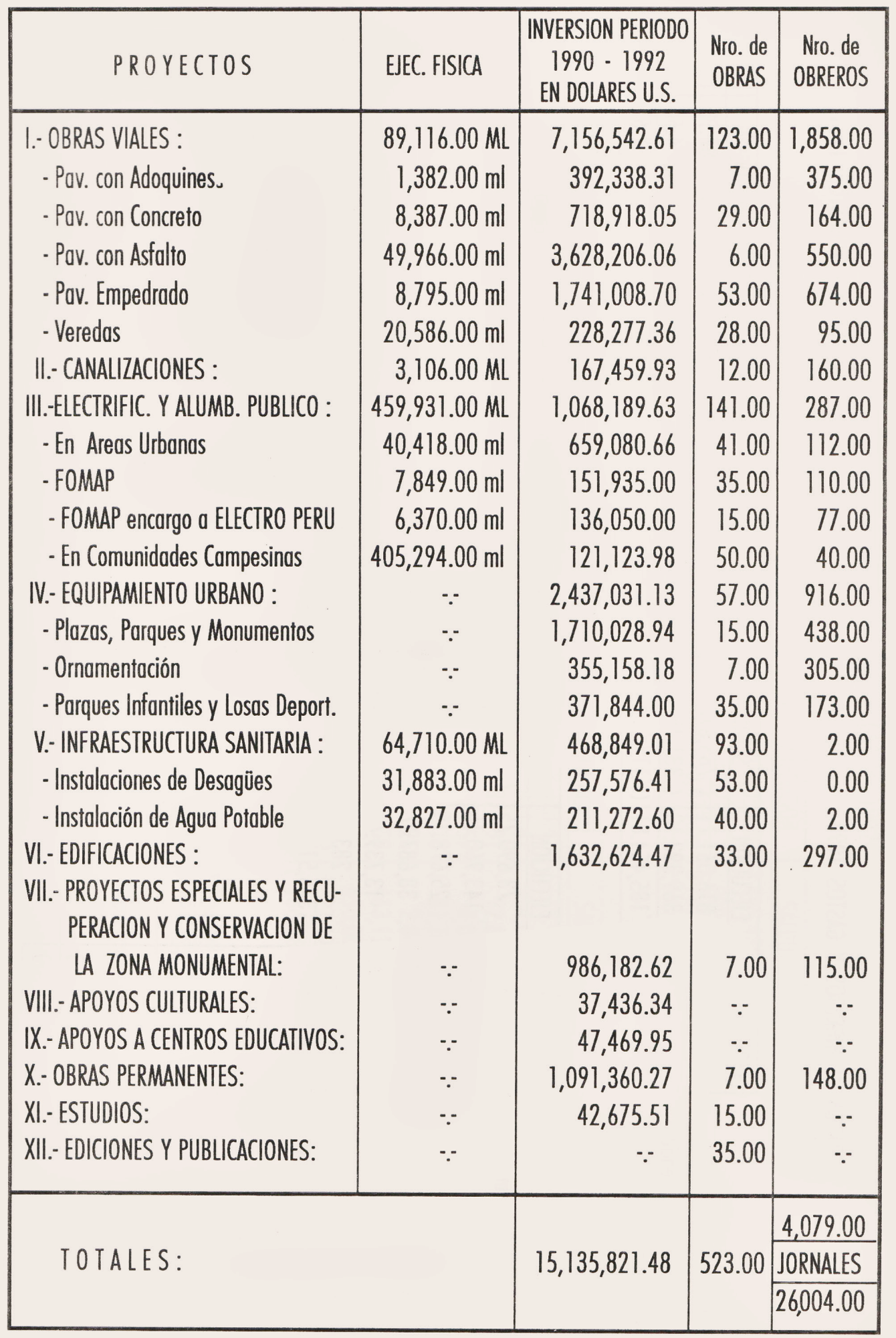

Figura 21. Resumen ejecución de obras, periodo 1990-1992. En Proyecto y Acciones Ejecutados. Ingresos y Gastos, por Municipalidad Del Qosqo, 1993. 
San Blas: Del ocaso al renacimiento. Paradigma temprano de gestión del patrimonio en el Sur Peruano. El CASO DEL BARRIO HISTÓRICO DE SAN BLAS DURANTE LA GESTIÓN MUNICIPAL 1990-1993

Magaly leonor Gallardo Del Castillo, Edgar Casaverde Zamalloa y Jorge Benjamín Pérez Bravo

doi: https://doi.org/10.21754/devenir.v6i11.632

\begin{tabular}{|c|c|c|c|c|}
\hline \multicolumn{5}{|c|}{ Proyecto: remodelación integral del barrio de San Blas } \\
\hline \multirow{3}{*}{ Nro } & \multicolumn{4}{|c|}{ Inversión 1992} \\
\hline & \multirow{2}{*}{ Proyecto } & \multirow{2}{*}{$\begin{array}{c}\text { Ejec. Fisica } \\
\text { ML }\end{array}$} & $\begin{array}{l}\text { Ppto. } \\
\text { Remodelación }\end{array}$ & $\begin{array}{l}\text { Ppto. } \\
\text { Iluminación }\end{array}$ \\
\hline & & & S/ & S/ \\
\hline 1 & Calle Pasñapacana & 76.00 & $\mathrm{~S} / 20,397.00$ & $S / 3,149.00$ \\
\hline 2 & Calle Kcanchipata & 87.00 & $S / 24,263.00$ & $S / 3,674.00$ \\
\hline 3 & Calle Atocsaycuchi & 256.00 & $\mathrm{~S} / 44,490.00$ & $\mathrm{~S} / 10,017.00$ \\
\hline 4 & Calle Pantaccalle & 141.00 & $\mathrm{~S} / 18,978.00$ & $S / 4,893.00$ \\
\hline 5 & Calle Quiscapata & 240.00 & $S / 53,372.00$ & $\mathrm{~S} / 5,179.00$ \\
\hline 6 & Calle Huarancallqui & 55.00 & $S / 13,545.00$ & $\mathrm{~S} / 2,517.00$ \\
\hline 7 & Calle Siete Angelitos & 120.00 & $\mathrm{~S} / 26,388.00$ & $S / 4,480.00$ \\
\hline 8 & Calle Curcurpata & 149.00 & $S / 17,790.00$ & $\mathrm{~S} / 5,594.00$ \\
\hline 9 & Calle Alabado & 113.00 & $\mathrm{~S} / 19,199.00$ & $S / 4,547.00$ \\
\hline 10 & Calle Carmen Alto & 233.00 & $S / 49,152.00$ & $S / 6,160.00$ \\
\hline 11 & Calle Carmen Bajo & 114.00 & $S / 26,159.00$ & $S / 3,920.00$ \\
\hline 12 & Plazoleta San Blas & 219.00 & $S / 105,458.00$ & $S / 11,513.00$ \\
\hline 13 & Calle Siete Diablitos & 82.00 & $\mathrm{~S} / 9,892.00$ & $\mathrm{~S} / 3,077.00$ \\
\hline 14 & Calle Uspacalle & 42.00 & $S / 11,262.00$ & $S / 1,680.00$ \\
\hline 15 & Calle Pumacchupan & 52.00 & $\mathrm{~S} / 11,933.00$ & $\mathrm{~S} / 1,957.00$ \\
\hline 16 & Calle Miracalcetas & 26.00 & $\mathrm{~S} / 8,957.00$ & $S / 1,120.00$ \\
\hline 17 & Calle Plazoleta & 50.00 & $S / 5,209.00$ & $S / 0.00$ \\
\hline 18 & Calle Asnoqchuton & 74.00 & $S / 15,920.00$ & $S / 2,517.00$ \\
\hline 19 & Calle Suytuccato & 155.00 & $S / 21,169.00$ & $S / 7,347.00$ \\
\hline 20 & Calle Cuesta San Blas & 117.00 & $S / 20,119.00$ & $\mathrm{~S} / 5,040.00$ \\
\hline 21 & Calle Tandapata & 713.00 & $S / 52,453.00$ & $S / 21,762.00$ \\
\hline 22 & Calle Saqrapata & 37.00 & $S / 11,350.00$ & $S / 2,029.00$ \\
\hline 23 & Calle Pumapaccha & 153.00 & $S / 44,716.00$ & $S / 5,633.00$ \\
\hline \multirow[t]{2}{*}{24} & Mirador Quiscapata & 102.00 & $\mathrm{~S} / 40,862.00$ & $\mathrm{~S} / 5,179.00$ \\
\hline & & 3406.00 & $\mathrm{~S} / 673,033.00$ & $\mathrm{~S} / 122,984.00$ \\
\hline \multirow{2}{*}{ TOTAL } & & 3406.00 & \multicolumn{2}{|c|}{$S / 796,017.00$} \\
\hline & & ML & \multicolumn{2}{|c|}{ SOLES } \\
\hline
\end{tabular}

En Proyecto y Acciones Ejecutados. Ingresos y Gastos, por Municipalidad Del Qosqo, 1993. 
devenir Vol. 6, N¹1, ENERO - JUNIO 2019, PP. 25-48 - ESTUDIOS I ISSN 2312-7562 I E-ISSN 2616-4949

UNIVERSIDAD NACIONAL DE INGENIERÍA, LIMA

doi: https://doi.org/10.21754/devenir.v6i11.632

que, provenientes desde la quebrada del Tullumayo, discurrían por allí hacia los campos de cultivo aledaños.

Para el desarrollo de estas intervenciones fue necesario contar con un equipo técnico muy hábil y con grandes potestades, rol que cumplieron el entrevistado Miguel A. Mostajo Hinojosa, como gerente técnico de la Municipalidad, y su equipo al realizar la constante retroalimentación que requerían dichas acciones.

La intervención llevada a cabo en el Barrio de San Blas durante la gestión 1990-1993 puede considerarse asertiva y valedera por los efectos alcanzados en el mejoramiento de la imagen del barrio; la apropiación social por parte del poblador del lugar, así sumado al proceso de concepción y construcción; y la combinación extraordinaria de capacidad de gestión y de participación ciudadana, motivada por la autoafirmación de la identidad local basada en la cultura prehispánica, auspiciada y avivada por los procesos de descentralización de la década de los 90, autentica aspiración de los pueblos ante la exacerbada centralización del Perú, cuyos efectos negativos a nivel nacional se viven hasta la actualidad.

Gracias a que la intervención contempló acciones de mejoramiento y potenciación de los atractivos turísticos de parte de la ciudad del Cusco, una de las acciones más importantes realizadas desde su incorporación en la lista del Patrimonio Mundial, Cusco adquirió un gran protagonismo a nivel mundial, lo cual fue el detonante de la masiva demanda turística actual.

Ello incidió en el impacto económico de la intervención, que fue positivo tanto en relación al valor del suelo como al aumento de la vocación y los servicios turísticos de la zona, lo cual se tradujo en el aumento de ingresos para sus pobladores.

Un logro transcendental constituye la participación activa de la población beneficiaria en la gestión y ejecución de la obra. Esta virtud se contrapone a las gestiones posteriores, que han operado a partir de programas prefabricados, sin incorporar a la población, desde una visión centralizada plagada de procesos burocráticos gubernamentales, carente de acciones y realizaciones, que a pesar del tiempo y la tecnología actual no han dado indicios de eficiencia ni diligencia.

La intervención aquí estudiada y su apuesta constituyen un acierto para su tiempo. Los objetivos fueron alcanzados en gran parte; sin embargo, debido la improvisación de las gestiones posteriores, faltas de visión válida y sostenible, la vocación inicial del Barrio de San Blas ha degenerado, dando lugar a un fenómeno no previsto: la gentrificación. Los habitantes originales hoy son extraños, problemática latente recientemente abordada. Existe una deuda estratégica en la visión y gestión de ciudad, deuda de las gestiones municipales posteriores, que se han excluido de la función fundamental que es el de hacer ciudad.

Por lo tanto, la intervención del Barrio de San Blas 1990-1993 ha sentado un precedente en modelo de gestión de intervención en barrios similares y en poblados de carácter histórico más allá de la región del Cusco. Los procedimientos normativos y administrativos se agilizaban a fuerza de voluntad política en favor de la celeridad necesaria: solo así Estrada Pérez justifica y logra su prolífica labor.

Sin embargo, también es necesario reconocer las debilidades de la gestión. La planificación urbana de la ciudad no estaba estructurada como organización formal: era efectiva pero no existían oficinas técnicas dedicadas a esta labor, que fue directamente realizada por el alcalde y su equipo, lo cual falló en asegurar la continuidad de la gestión emprendida. Además, la concepción de los proyectos en algunos aspectos prescindió de la consulta de especialistas, por lo que recibió muchas críticas al respecto en el ámbito nacional. 
San Blas: Del ocaso al renacimiento. Paradigma temprano de gestión del patrimonio en el Sur Peruano.

EL CASO DEL BARRIO HISTÓRICO DE SAN BLAS DURANTE LA GESTIÓN MUNICIPAL 1990-1993

Magaly Leonor Gallardo Del Castillo, Edgar Casaverde Zamalloa y Jorge Benjamín Pérez Bravo

doi: https://doi.org/10.21754/devenir.v6i11.632

\section{Conclusiones generales}

La tarea de salvaguarda del patrimonio, entendida mayormente como conservación, está deficientemente razonada por las autoridades. Según el pensamiento vanguardista de hoy, la ciudad histórica no debe estar divorciada del desarrollo actual de la ciudad; sin embargo, las autoridades o gestiones, tanto regionales como municipales, en las últimas décadas han eludido su responsabilidad: no han prestado atención al centro histórico, como si este no fuese su competencia, ni tampoco han abordado los problemas urbanos con la debida atención. Más bien, han dejado en manos del sector privado, por lo general carente de visión integral, casi el total de acciones relacionadas al manejo de la ciudad, lo cual ha acarreado problemas como la gentrificación y la consecuente pérdida de los valores inmateriales del centro histórico.

Los niveles de coordinación interinstitucional, en relación a la aspiración a ser una ciudad sostenible, son muy escasos. Cada institución actúa de forma ensimismada, sin una guía, un plan o una visión. Dicha guía, en este caso, tendría que ser provista, por jerarquía, por el Gobierno Regional del Cusco, pues las poblaciones por su crecimiento conurbado cubren grandes áreas de territorio, que involucran varios distritos y provincias de la región. El centro histórico del Cusco, a pesar de que sostiene buena parte de la economía cusqueña a partir del turismo, no está siendo atendido de forma pertinente.

En la gestión de Estrada Pérez, es posible observar un componente muy importante que las gestiones posteriores no han sabido ni podido replicar: la conexión con los diferentes actores de la ciudad, la consecución de visiones conjuntas para intervenir en ella desde su complejidad, lo que permitió obtener un balance constructivo entre los múltiples intereses involucrados. Esta conexión directa, empática y comprometida entre autoridad y vecino, logró concretar exitosamente la intervención.

\section{Referencias}

Araoz, H. (2010). La dinámica de los centros históricos. Llaqta, 1, 3-8.

Calvo Calvo, R. (1995). Qosqo sociedad e ideologia. Siglo XX (Municipalidad del Cusco Ed., Vol. 1). Cusco, Perú: Yañez.

Calvo Calvo, R. (1999). La tradición Representación de la urbe Andina Cusqueña en el siglo XX. Cusco, Perú: Municipalidad de Santiago del Cusco.

Cañari Arce, C. (2008.). Las competencias y funciones especificas de los Gobiernos locales. Lima, Perú. Recuperado de https://es.slideshare.net/munijm/las-competencias-y-funciones-especficas-de-los-gobiernos-locales-presentation

Carrión, F. (2000). Desarrollo cultural y gestión en centros históricos. Quito, Ecuador: Facultad Latinoamericana de Ciencias Sociales.

Castillo Garcia, R. F. (2016). Instituciones representativas del urbanismo en el Perú 1946-2015. PAIDEA , 5(6), 13-23.

Contraloría General de la República. (2014). Estudio del proceso de descentralización en el Perú. Lima, Perú: Autor.

Covarrubias Pozo, J. M. (1958). Cuzco colonial y su arte: Apuntes para la historia de los monumentos coloniales del Cuzco (Vol. 1). Cusco, Perú: H. G. Rozas.

Donato, A. (2009). La formación de las parroquias y la nobleza incaica en la ciudad del Cuzco. L. Nieto Degregori (Ed.), El ombligo se pone piercing: Identidad, patrimonio y cambios en el Cuzco (pp. 11-48). Cusco, Perú: Centro Guaman Poma de Ayala.

García, U. J. (28 de julio de 1921). El Sol del Cusco, p. 4.

Hayakawa Casas, J. C. (2015). Gestión del patrimonio cultural y centros historicos latinoamericanos (2da ed.). Lima, Perú: ediFAUA.

Krüggeler, T. (1985). Indianas, workers and the arrival of Modernity. Las Américas, 56(2), 161-189.

López Soria, J. I. (2003). Para una filosofía de la ciudad. Urbes, 1(1), 13-28. 
devenir Vol. 6, N¹1, ENERO - JUNIO 2019, PP. 25-48 - ESTUDIOS I ISSN 2312-7562 | E-ISSN 2616-4949

UNIVERSIDAD NACIONAL DE INGENIERÍA, LIMA

doi: https://doi.org/10.21754/devenir.v6i11.632

Municipalidad del Qosqo. (1933). Mi nuevo San Blas. Cusco, Perú: Autor.

Municipalidad Del Qosqo. (1993). Proyecto y acciones ejecutados. Ingresos y gastos. Cusco, Perú: Autor.

Municipalidad del Qosqo. (1995). Diccionario enciclopédico del Qosqo (A. Avendaño, Ed.). Cusco, Perú: Autor.

Municipalidad Del Cusco. (2018). Plan maestro del Centro Histórico de Cusco 2018-2028. Cusco, Perú: Autor.

Nieto Degregori, L. (1996). El Cusco en peligro. Debate, 8, 54-57.

Nieto Degregori, L. (Ed.). (2009). El ombligo se pone piercing. Identidad, patrimonio y cambios en el Cuzco (Vol. 1). Cusco, Perú: Servicios Gráficos JMD.

Ordenanza Municipal N02-A/MQ-SG-92. Código Municipal para la protección de la Ciudad Histórica del Qosqo. (14 de junio de 1992). Diario Oficial El Peruano.

Pino Zambrano, V. (2004). La experiencia del Alcalde Daniel Estrada Pérez. Perú: Innova Arquitectura Integral.

Samanez, R. (2010). A propósito de los 25 años de la inclusión del Cusco en la Lista del Patrimonio Mundial. Llaqta, 1, 13-16.

San Blas. La destrucción de un barrio tradicional. (1997). Cusco, Perú: Centro Guamán Poma de Ayala.

Valencia Becerra, T. A. (2007). Nuevas relaciones, viejas tradiciones en San Blas. Lima, Perú: Pontificia Universidad Católica del Perú.

Ministerio de Cultura. (s. f.). Lineamientos de política cultural. Recuperado de http://www.cultura. gob.pe/es/informacioninstitucional/lineamientos 